\title{
Estudos dos compostos orgânicos voláteis precursores de ozônio na cidade de São Paulo
}

\section{Studies of the volatile organic compounds precursors of ozone in São Paulo city}

\author{
Débora Souza Alvim \\ Licenciada em Química pela Universidade de São Paulo (USP). Doutoranda do Instituto de Pesquisas Energéticas e Nucleares (IPEN) da USP. \\ Bolsista do Conselho Nacional de Desenvolvimento Científico e Tecnológico (CNPq)
}

Luciana Vanni Gatti

Bacharel em Química pela USP. Pesquisadora do IPEN. Docente de pós-graduação da USP. Pesquisadora do CNPq nível 2

Maria Helena dos Santos

Engenheira Ambiental pela Faculdade Oswaldo Cruz (FOC)

Amélia Yamazaki

Engenheira Química pela FOC. Tecnologista do IPEN

\section{Resumo}

O ozônio é o principal problema de poluição do ar na cidade de São Paulo. Este estudo, que foi realizado em uma estação de monitoramento da qualidade do ar da Companhia de Tecnologia de Saneamento Ambiental (CETESB), enfoca a elucidação dos principais compostos orgânicos voláteis precursores de ozônio na atmosfera paulistana. Foram coletadas 36 amostras nos meses de agosto e setembro de 2006, nos quais o consumo de etanol era de aproximadamente $50 \%$ nesta época. Foram quantificadas 69 espécies de compostos orgânicos voláteis, nos quais os dez compostos mais importantes na formação de $\mathrm{O}_{3}$ foram: 1-buteno (6,8\%), eteno (6,5\%), formaldeído (6,1\%), acetaldeído (5,5\%), tolueno (4,8\%), 1-etil-4-metilbenzeno (3,7\%), trans-2-penteno (3,7\%), propeno (3,7\%), trans-2-buteno (3,5\%) e 1-metilciclopenteno (3,5\%). As classes mais abundantes em concentração no ar foram: alcanos (45\%), alcenos (26\%), aromáticos (14\%), aldeídos (13\%) e alcadienos (2\%).

Palavras-chave: compostos orgânicos voláteis; potencial de formação de ozônio; poluição atmosférica; São Paulo.

\section{Abstract}

Ozone is the main problem of air pollution in the city of São Paulo. This study, which was carried out in the Brazilian Basic Sanitation Engineering Company (CETESB, acronym in Portuguese) monitoring station of air quality, focused on the elucidation of the main volatile organic compounds ozone precursors in São Paulo atmosphere. Thirty-six samples were collected in August and September 2006, when the consumption of ethanol was about $50 \%$, 69 species of volatile organic compounds were quantified, the ten major urban pollutants compounds in the formation of $\mathrm{O}_{3}$ were: 1-butene (6.8\%), ethylene $(6.5 \%)$, formaldehyde $(6.1 \%)$, acetaldehyde (5.5\%), toluene (4.8\%), 1-ethyl-4-methylbenzene (3.7\%), trans-2-pentene (3.7\%), propylene (3.7\%), trans-2-butene (3.5\%), and 1-methylcyclopentene (3.5\%). The most abundant classes of air concentration were: alkanes (45\%), alkenes (26\%), aromatics (14\%), aldehydes (13\%), and alkadyenes (2\%).

Keywords: volatile organic compounds; ozone production potential; air pollution; São Paulo. 


\section{Introdução}

A poluição atmosférica, nas regiões urbanas, tem aumentado devido ao aumento do número de veículos motorizados em circulação e à crescente atividade industrial. A qualidade do ar urbano tem causado sérios problemas às condições de vida das pessoas, das plantas e dos animais que vivem nas cidades e arredores.

A região metropolitana de São Paulo (RMSP) possui uma área de 8.051 km², com uma população superior a 19 milhões de habitantes, distribuída em uma área urbanizada e de maneira desordenada em $1.747 \mathrm{~km}^{2}$. A frota veicular de 9,7 milhões de veículos é composta por 7,9 milhões de veículos do ciclo Otto, 515 mil veículos a diesel e 1,3 milhão de motos. Os veículos são responsáveis pela emissão para a atmosfera de 1,52 milhões de toneladas por ano de monóxido de carbono, representando $97 \%$ do total da emissão e 370,5 mil t/ano de hidrocarbonetos, representando 97\%. Na frota atual da RMSP, o álcool etílico, considerando o anidro e o hidratado, corresponde a $65,6 \%$ do total de combustível consumido (veículos a etanol - 9,9\%; gasool - 53,6\% e veículos flex-17,8\%), as motocicletas representam 13,4\% e os veículos a diesel representam 5,3\% (CETESB, 2010).

Apesar das consideráveis reduções nas emissões veiculares com programas de melhoria da tecnologia dos motores (PROCONVE), ainda são frequentes os dias em que a concentração de ozônio $\left(\mathrm{O}_{3}\right)$ na RMSP ultrapassa os padrões nacionais de qualidade do ar. Enquanto o número de ultrapassagens do padrão para CO na RMSP decresceu de 18 para 0 de 1999 até 2010, o número de dias em que o padrão de $\mathrm{O}_{3}$ foi ultrapassado caiu de 109 para 57 no mesmo período, a redução do $\mathrm{O}_{3}$ não foi tão significativa, sendo este o pior problema de poluição atualmente na RMSP (CETESB, 2010).

Diante da dificuldade em se reduzir os níveis de $\mathrm{O}_{3}$ na RMSP, este estudo tem como principal objetivo apontar os principais compostos orgânicos voláteis (COV) precursores de ozônio na atmosfera da cidade de São Paulo.

A principal fonte de $\mathrm{O}_{3}$ na troposfera é a interação entre seus gases precursores $\mathrm{NO}_{\mathrm{X}}$, COV e $\mathrm{CO}$ em presença de radiação ultravioleta $(\boldsymbol{\lambda} \leq 430 \mathrm{~nm})$ (SEINFELD; PANDIS, 2006). O O é um potente oxidante, seus altos níveis na troposfera causam danos à colheita e à vegetação natural. Nos EUA, projeções indicam que o poluente provoca perdas de bilhões de dólares para a horticultura e a agricultura (OLSZYK; THOMPSON; POE, 1988). O O troposférico também causa efeitos na função respiratória de crianças e adultos, aumento na frequência das crises de asma, redução do desempenho de atletas, estresse adicional em pacientes com doenças pulmonares obstrutivas crônicas e inflamação dos pulmões (CETESB, 2010).

Estudos envolvendo análises dos COV presentes na atmosfera têm sido realizados no intuito de se obter um melhor conhecimento sobre a composição, a concentração, o fluxo e as fontes de emissão em áreas urbanas (BLAKE; ROWLAND, 1995; DERWENT et al., 2000; NA; KIM, 2001; HSIEH; TSAI, 2003; BARLETTA et al., 2005; GUO et al., 2006; QUIN et al., 2007; LANGFORD et al., 2010). Os estudos sobre os compostos orgânicos presentes na atmosfera urbana das cidades brasileiras ainda são poucos e estão concentrados nas cidades de São Paulo, Rio de Janeiro e Porto Alegre, tais como: GROSJEAN et al., 1998; MACHADO, 2003; PRETTO, 2004; VASCONCELLOS; CARVALHO; POOL, 2005; ORLANDO et al., 2010.

Além dos COV serem importantes contribuintes na formação do $\mathrm{O}_{3}$, eles também apresentam caráter prejudicial à saúde. Compostos como o benzeno, o tolueno, e o m, p e o-xileno atraíram a atenção do ponto de vista da formação do ozônio e da saúde humana. A incidência aumentada de leucemia foi observada nos seres humanos ocupacionalmente expostos ao benzeno, e outros aromáticos são apontados como provavelmente carcinogênicos (USEPA, 1993).

Depois dos hidrocarbonetos, os aldeídos são os mais abundantes gases orgânicos presentes na atmosfera. A utilização do etanol como combustível veicular contribui significativamente à emissão dos aldeídos. O formaldeído é irritante aos olhos e ao trato respiratório, sendo apenas descrito como altamente suspeito de ser um composto carcinogênico (CETESB, 2010).

Os COV são de interesse para reguladores da qualidade do ar por várias razões, já que alguns são considerados tóxicos e poluentes perigosos ao ar. Outra importante razão é o fato deles serem precursores de poluentes secundários do ar, tais como: ozônio, nitrato de peroxiacetila (PAN) e aerossóis secundários orgânicos.

\section{Metodologia}

\section{Amostragem dos COV}

A metodologia de amostragem dos COV utilizada neste trabalho foi baseada no método do TO-15 da United States Environmental Protection Agency - USEPA (1999), que consiste na amostragem em canisters, seguido de pré-concentração criogênica da amostra e posterior análise por cromatografia gasosa com diversos detectores. As amostragens foram realizadas utilizando globos de aço inox de $6 \mathrm{~L}$ (canister), eletropolidos internamente. Os globos de aço inoxidável foram limpos por um sistema comercial da Xontech (USA), que utiliza como ferramentas de limpeza o aquecimento $\left(120^{\circ} \mathrm{C}\right)$, alto vácuo e vapor d'água com ciclos alternados. Durante este trabalho, foram coletadas 36 amostras na estação da Companhia de Tecnologia de Saneamento Ambiental (Cetesb) Cerqueira César, localizada em um ponto de grande fluxo de veículos, a 814 metros de altitude. Segundo dados da Cetesb, a principal fonte de poluição nesta localidade é proveniente da frota veicular (CETESB, 2010).

As 36 amostras foram coletadas durante os dias 10, 15, 16 (desde às 6 às 18 horas) e 17 (6 às 10 horas) no mês de agosto e 14 (6 às 18 horas), 15 (6 às 10 horas), 27 (6 às 18 horas) e 28 (6 às 10 horas), 
em setembro de 2006. O procedimento de amostragem foi realizado integrando duas horas em cada amostra, utilizando controladores de fluxo de massa fixados em $50 \mathrm{~mL} \cdot \mathrm{min}^{-1}$, integrando $6 \mathrm{~L}$ em duas horas. As amostragens de aldeídos e hidrocarbonetos foram realizadas na mesma entrada de ar dos monitores de gases da estação telemétrica da CETESB, as análises de CO foram realizadas pelo monitor deste poluente da CETESB (PRETTO, 2004; CETESB, 2007; 2010).

No período entre o dia 10 de agosto até 28 de setembro de 2006, a velocidade média do vento foi de $1,63 \mathrm{~m} \cdot \mathrm{s}^{-1}$, a precipitação acumulada foi de $60 \mathrm{~mm}$, ocorreram 15 inversões térmicas abaixo de $200 \mathrm{~m}$ da superfície e $14,6 \%$ dos dias foi de calmaria (velocidade do vento inferior a $0,5 \mathrm{~m} / \mathrm{s}$ ). Analisando os dados meteorológicos durante esta campanha, pode-se caracterizar como um período seco, de grande estabilidade atmosférica e formação de inversão térmica muito próxima à superfície (abaixo de 200 m). Estas condições são desfavoráveis à dispersão dos poluentes, favorecendo o acúmulo dos poluentes e promovendo as altas concentrações de poluentes observadas durante o período de inverno na RMSP (CETESB, 2007).

\section{Identificação e quantificação dos COV não-metânicos}

Foram utilizados dois equipamentos para a análise dos COV. Um cromatógrafo gasoso (VARIAN 3800), com detecção simultânea de espectrometria de massas (DEM) (SATURN 2000), e ionização de chama (DIC). O DEM foi utilizado para realizar a identificação do COV nas amostras, enquanto que o de ionização de chama foi utilizado para a quantificação dos compostos. Esse sistema foi utilizado para analisar COV que tenham a partir de quatro carbonos e para identificar e quantificar COV leves (C2 a C3), sendo que este sistema utiliza um cromatógrafo (VARIAN 3800) com detector de ionização de chama.

As amostras foram analisadas diretamente na fase gasosa, utilizando a técnica de pré-concentração criogênica e um tubo de 1/8" preenchido com pérola de vidro silanizada, em temperatura de $-180^{\circ} \mathrm{C}$, no qual foram concentrados $200 \mathrm{~mL}$ de amostra. Utilizouse uma coluna apolar de $60 \mathrm{~m}$ de comprimento, com $1 \mu \mathrm{m}$ de espessura de fase estacionária e 0,32 mm de diâmetro interno (DI). A programação do forno cromatográfico utilizou uma variação de temperatura de $6^{\circ} \mathrm{C}$. $\mathrm{min}^{-1}$, de -50 a $200^{\circ} \mathrm{C}$

No final da coluna cromatográfica, a amostra foi dividida em dois detectores diferentes, sendo uma parte enviada para o DEM e outra para o DIC, utilizando-se uma conexão em "T" de volume morto da Valco. Para compensar a diferença de pressão entre os dois detectores, foram utilizados um tubo de $50 \mathrm{~cm}$, sem fase estacionária, de DI de 0,1 mm para o DEM e um de $25 \mathrm{~cm}$ de comprimento e 0,32 mm de DI para o DIC.

No método para a quantificação dos COV leves, utilizou-se uma coluna PLOT de sílica fundida de $\mathrm{Al}_{2} \mathrm{O}_{3} / \mathrm{Na}_{2} \mathrm{SO}_{4}$ (polar) com $50 \mathrm{~m}$ de comprimento, 0,53 $\mathrm{mm}$ de DI e $10 \mu \mathrm{m}$ de espessura de fase estacionária. A etapa da pré-concentração é igual à do método descrito anteriormente. A faixa de temperatura utilizada foi de -50 a $180^{\circ} \mathrm{C}$, com uma rampa de temperatura no forno cromatográfico de $10^{\circ} \mathrm{C} \cdot \mathrm{min}^{-1}$ e detecção com ionização de chama.

Para as análises de formaldeído e acetaldeído realizadas pela CETESB, foi utilizada a norma TO-11 da USEPA (1997), que consiste na realização de amostragens em cartuchos de sílica amorfa $\left(\mathrm{SiO}_{2}\right)$ com grupos $\mathrm{OH}$ ligados à superfície, com solução de 2,4-dinitrofenilhidrazina (DNPH) e análise por cromatografia líquida de alta eficiência (CLAE). Foram usadas as amostras correspondentes às realizadas com canister. As amostras foram eluídas dos cartuchos utilizando acetonitrila, a coluna utilizada foi do tipo C18 de $250 \mathrm{~mm}$ de comprimento e 4,6 mm de DI, fase móvel com 60\% de acetonitrila e 40\% de água (v/v), vazão da fase móvel: 1,0 mL. $\mathrm{min}^{-1}$, utilizando detector ultravioleta na faixa de $360 \mathrm{~nm}$. Para curva de calibração, soluções padrões do formaldeído e acetaldeído da Supelco foram utilizadas.

Para determinação das concentrações de $\mathrm{CO}$, realizadas pela rede telemétrica da CETESB, utilizou-se o analisador Gas Filter Correlation da Thermo Environmental Instruments Inc, modelo $48 \mathrm{C}$, que mede a absorção da radiação infravermelha $(\lambda=4,6 \mu \mathrm{m})$ absorvida pelo CO durante 24 horas, e a média horária é calculada de uma em uma hora (PRETTO, 2004; CETESB, 2007; 2010).

Os valores médios de quilômetros $(\mathrm{km})$ de congestionamento na cidade de São Paulo foram medidos pela Companhia de Engenharia de Tráfego (CET), que é uma média efetuada pela CET para o ano de estudo, o valor do $\mathrm{km}$ foi dividido por 50 para facilitar sua visualização na Figura 1 (CET, 2006).

A quantificação dos hidrocarbonetos foi realizada utilizandose quatro misturas de padrões gasosos produzidos e certificados pela SCOTT SPECIALISTY, com o emprego de curvas analíticas de padrões certificados. As misturas padrões gasosas utilizadas foram de alcanos, alcenos, aromáticos e TO-14 (mistura de 39 compostos: estireno, tetracloroetileno, 1,2,4-triclorobenzeno, tricloroetileno, triclorofluorometano, 1,2,4-trimetilbenzeno, 1,3,5-

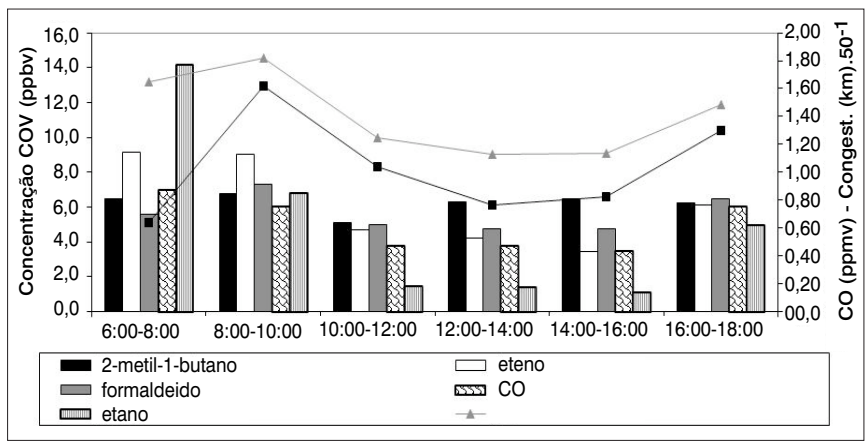

Figura 1 - Distribuição das concentrações médias ao longo do dia para monóxido de carbono (CO) (ppmv), dos cinco compostos orgânicos voláteis (COV) (ppbv) mais abundantes registrados na estação CETESB Cerqueira César e quilômetros de congestionamento $(\mathrm{km})$ médio dividido por 50 na cidade de São Paulo, medido pela CET. 0 valor de km de congestionamento foi divido por 50 para ficar na mesma escala no gráfico 
trimetilbenzeno, tolueno, cloreto de vinila, m-xileno, o-xileno, p-xileno e outros), preparadas na concentração de 1,0 ppmv e balanceadas em nitrogênio. As concentrações das curvas foram produzidas utilizando um multicalibrador da Thermo Environmental Instruments Inc, modelo 146C, diluindo o s padrões certificados em nitrogênio 5.0. Para a quantificação de compostos não-contidos nos padrões, os fatores de resposta da mesma classe dos compostos como alcanos, alcenos e aromáticos foram aplicados. O fator de resposta (FR) é a razão entre a área obtida no cromatograma, dividida pela concentração, multiplicada pelo número de carbonos do composto em questão, segundo a Equação 1. As amostras foram analisadas em triplicata, os valores são referentes às médias de três resultados mais ou menos o valor das incertezas associadas, e os desvios padrões calculados a partir das médias das triplicatas das amostras (ABNT/INMETRO, 2003). Foram encontrados 69 picos nos cromatogramas.
$F R=$ $\frac{\text { Area }}{\text { concentração } \times \text { número de carbonos }}$

Equação 1

Para a determinação de quanto cada espécie de COV pode contribuir para a formação de $\mathrm{O}_{3}$, aplicou-se o método de Carter, que consiste no produto da concentração de COV em $\left(\mu \mathrm{g} . \mathrm{m}^{-3}\right)$ pelo valor de seu máximo incremento de reatividade (MIR). Para compor a escala MIR, Carter utilizou mecanismos fotoquímicos de reações atmosféricas envolvidas na formação do $\mathrm{O}_{3}$, sob várias condições de NOx, em 39 cenários que representam áreas urbanas diferentes nos EUA (CARTER, 2003). Na tabela MIR, existem fatores para $118 \mathrm{COV}$. Para o cálculo da concentração em $\mu \mathrm{g} \cdot \mathrm{m}^{-3}$ de cada COV, foram considerados: a constante universal dos gases perfeitos (8.314 J.K $\mathrm{K}^{-1} \cdot \mathrm{mol}^{-1}$ ); a temperatura ambiente (298 K); a pressão atmosférica (101350 Pa); a massa molar (MM) de cada espécie de COV e a concentração média destes COV em ppbv. Este resultado (em $\left.\mu \mathrm{g} . \mathrm{m}^{-3}\right)$ foi multiplicado

Tabela 1 - Compostos orgânicos voláteis medidos na estação CETESB Cerqueira César, em ordem decrescente de quantidade ozônio formada (g0/ $\mathrm{gCOV}^{*}$ ) e sua concentração em ppbv na atmosfera, referente às médias das 36 amostragens realizadas neste estudo

\begin{tabular}{|c|c|c|c|c|c|}
\hline Compostos & Conc.(ppbv) & $\mathrm{gO}_{3} / \mathrm{gCOV}$ & Compostos & Conc.(ppbv) & $\mathrm{gO}_{3} \mathrm{gCOV}$ \\
\hline 1-buteno & $2,57 \pm 0,06$ & 60,7 & metilcicloexano & $0,58 \pm 0,02$ & 4,64 \\
\hline Eteno & $5,61 \pm 0,15$ & 58,4 & 3-metilexano & $0,59 \pm 0,02$ & 4,47 \\
\hline Formaldeído & $5,00 \pm 0,01$ & 55,1 & ciclopentano & $0,51 \pm 0,01$ & 3,94 \\
\hline Acetaldeído & $4,00 \pm 0,01$ & 49,3 & Heptano & $0,73 \pm 0,03$ & 3,83 \\
\hline Tolueno & $2,86 \pm 0,12$ & 42,8 & hexeno & $0,18 \pm 0,01$ & 3,82 \\
\hline 1-etil-4-metilbenzeno & $0,69 \pm 0,03$ & 33,6 & 3,3-dimetil-1-buteno & $0,18 \pm 0,01$ & 3,75 \\
\hline trans-2-penteno & $1,13 \pm 0,03$ & 33,2 & cicloexano & $0,67 \pm 0,02$ & 3,37 \\
\hline trans-2-buteno & $0,98 \pm 0,02$ & 31,3 & 2-metil-1-penteno & $0,18 \pm 0,01$ & 3,21 \\
\hline Propeno & $1,66 \pm 0,01$ & 33,1 & 2-metil-hexano & $0,48 \pm 0,02$ & 2,70 \\
\hline 1-metilciclopenteno & $0,66 \pm 0,02$ & 30,9 & Benzeno & $0,96 \pm 0,03$ & 2,51 \\
\hline 2-metilbutano & $6,21 \pm 0,09$ & 30,6 & Propano & $2,09 \pm 0,03$ & 2,11 \\
\hline 1,3,5-trimetilbenzeno & $0,50 \pm 0,02$ & 27,6 & indano & $0,13 \pm 0,01$ & 1,99 \\
\hline cis-2-buteno & $0,86 \pm 0,02$ & 26,1 & propilbenzeno & $0,17 \pm 0,01$ & 1,84 \\
\hline p-xileno & $1,39 \pm 0,13$ & 25,7 & octano & $0,33 \pm 0,02$ & 1,71 \\
\hline m-xileno & $0,54 \pm 0,02$ & 24,9 & 2-metil-heptano & $0,27 \pm 0,01$ & 1,51 \\
\hline Isopreno & $0,81 \pm 0,02$ & 24,1 & 1,3-dimetilcicloexano & $0,15 \pm 0,01$ & 1,48 \\
\hline 2-metil-2-buteno & $1,24 \pm 0,03$ & 23,2 & Nonano & $0,28 \pm 0,01$ & 1,41 \\
\hline o-xileno & $0,69 \pm 0,02$ & 22,4 & 1,3-dimetilciclopentano & $0,16 \pm 0,01$ & 1,38 \\
\hline cis-2-penteno & $0,71 \pm 0,02$ & 20,9 & 2,3-dimetilbutano & $0,31 \pm 0,01$ & 1,25 \\
\hline 1,3-butadieno & $0,66 \pm 0,02$ & 19,8 & decano & $0,25 \pm 0,01$ & 1,21 \\
\hline 1-penteno & $0,80 \pm 0,02$ & 17,9 & etilcicloexano & $0,13 \pm 0,01$ & 1,04 \\
\hline 1,2,3-trimetilbenzeno & $0,31 \pm 0,02$ & 17,2 & Etano & $2,50 \pm 0,07$ & 0,95 \\
\hline Ciclopenteno & $0,65 \pm 0,02$ & 13,4 & undecano & $0,19 \pm 0,02$ & 0,90 \\
\hline Etilbenzeno & $0,95 \pm 0,03$ & 11,5 & 2,3-dimetilpentano & $0,13 \pm 0,01$ & 0,82 \\
\hline Butano & $3,40 \pm 0,01$ & 10,8 & 3-metileptano & $0,13 \pm 0,01$ & 0,81 \\
\hline 2-metilpentano & $1,67 \pm 0,04$ & 10,6 & 1,1,3-trimetilcicloexano & $0,10 \pm 0,01$ & 0,70 \\
\hline Pentano & $2,31 \pm 0,05$ & 10,5 & Dodecano & $0,12 \pm 0,01$ & 0,55 \\
\hline Metilciclopentano & $1,23 \pm 0,04$ & 10,3 & trans-1,2-etilciclopentano & $0,05 \pm 0,01$ & 0,46 \\
\hline 1-etil-2-metilbenzeno & $0,20 \pm 0,01$ & 9,73 & Limoneno & $0,02 \pm 0,01$ & 0,44 \\
\hline 3-metilpentano & $1,10 \pm 0,03$ & 8,03 & dimetilciclopentano & $0,05 \pm 0,01$ & 0,43 \\
\hline Hexano & $1,22 \pm 0,04$ & 6,24 & cis-1,2-dimetilciclopentano & $0,05 \pm 0,01$ & 0,43 \\
\hline 1,1-dimetilciclopropano & $1,41 \pm 0,03$ & 6,15 & 2,4-dimetilpentano & $0,03 \pm 0,01$ & 0,20 \\
\hline 2-hexeno & $0,18 \pm 0,01$ & 5,23 & 2,2,4-trimetilpentano & $0,02 \pm 0,01$ & 0,13 \\
\hline Isobutano & $1,52 \pm 0,01$ & 4,88 & Estireno & $0,01 \pm 0,01$ & 0,08 \\
\hline Naftaleno & $0,28 \pm 0,02$ & 4,78 & & & \\
\hline
\end{tabular}

*quantos gramas de ozônio são formados para cada grama de uma determinada espécie de COV. 
pelo valor da escala MIR, para cada espécie de COV, obtendo quantos gramas foram formados de $\mathrm{O}_{3}$ a partir de um grama de $\operatorname{COV}\left(\mathrm{O}_{3} \mathrm{~g} /\right.$ COV g), segundo a Equação 2.

$\left(O_{3} g \div \mathrm{COVg}\right)=\{[(\mathrm{MM} \times \mathrm{P}) \div(\mathrm{T} \times R)] \times[C O V s] \div 1000\} \times \mathrm{MIR}$

Equação 2

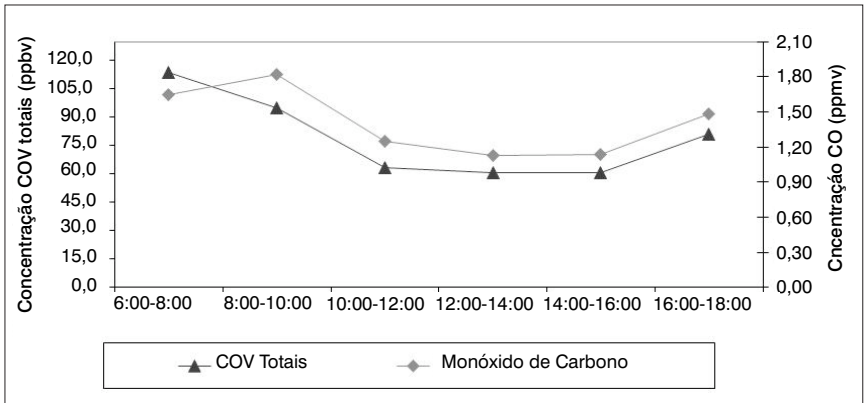

Figura 2 - Concentração média dos compostos orgânicos voláteis (COV) totais (ppbv) e monóxido de carbono (CO) (ppmv) amostrados durante os oito dias de campanha deste estudo, a cada duas horas, das 6 às 18 horas, na estação CETESB Cerqueira César

\section{Resultados}

Observa-se, na Figura 2, a correlação entre as concentrações médias de $\mathrm{CO}$ e COV totais para as 36 amostragens realizadas no período estudado.

As concentrações médias dos COV totais variaram de 57,1 ppbv (mínimo: 12 às 14 horas) a 96,7 ppbv (máximo: 6 às 8 horas), enquanto que o $\mathrm{CO}$ variou de 1,14 ppmv (12 às 14 horas) a 1,78 ppmv (8 às 10 horas). A Figura 1 mostra a média das concentrações dos cinco principais COV (ppbv) e CO (ppmv), no horário das 6 às 18 horas, e o valor médio de $\mathrm{km}$ de congestionamento na cidade de São Paulo, medido pela CET e dividido por 50 para facilitar sua visualização na mesma figura.

Na Tabela 1 são apresentados os 69 compostos identificados neste trabalho, em ordem decrescente de gramas de ozônio formado para cada um grama de $\mathrm{COV}\left(\mathrm{gO}_{3} / \mathrm{gCOV}^{*}\right)$, e as concentrações médias em ppbv destes compostos e suas incertezas associadas referentes às médias das 36 amostragens realizadas neste estudo.

A Tabela 2 compara os níveis de compostos a partir de C2 mais abundantes da RMSP com outras cidades do mundo.

Tabela 2 - Comparação entre os 15 hidrocarbonetos (ppbv) mais abundantes neste estudo e em outros centros urbanos

\begin{tabular}{|c|c|c|c|c|c|c|c|}
\hline & Compostos & São Paulo a & Cidado do México b & Taiwan ${ }^{c}$ & Dallas $^{d}$ & Seule & Londres $^{f}$ \\
\hline 1 & i-pentano & 6,2 & 19,4 & - & 6,1 & 2,3 & 4,1 \\
\hline 2 & Eteno & 5,6 & 21,6 & 7,2 & 2,8 & 5,9 & 3,5 \\
\hline 3 & n-butano & 3,4 & 70,3 & - & 4,6 & 3,8 & 4,9 \\
\hline 4 & Tolueno & 2,9 & 21 & 7,3 & 6 & 6,4 & 3,6 \\
\hline 5 & 1-buteno & 2,6 & 2,1 & 2,1 & - & - & - \\
\hline 6 & Etano & 2,5 & 14 & 9,7 & 9,5 & 3,8 & 3,4 \\
\hline 7 & n-pentano & 2,3 & 14,4 & 2,6 & 3 & 1,3 & 0,9 \\
\hline 8 & Propano & 2,1 & 158 & 6,8 & 8,5 & 7,8 & 2,6 \\
\hline 9 & $M+p$-xileno & 1,9 & - & - & 2,8 & 2,3 & 2,1 \\
\hline 10 & Propeno & 1,7 & - & 5,5 & - & 1,8 & 2,1 \\
\hline 11 & 2 e 3-metilpentano & 1,7 & 13,4 & - & - & 0,9 & - \\
\hline 12 & i-butano & 1,5 & 33 & 2,6 & 2,1 & 1,5 & 2,6 \\
\hline 13 & 1,1-diM-ciclopropano & 1,4 & - & - & - & - & - \\
\hline 14 & Metilciclopentano & 1,2 & - & - & - & - & - \\
\hline 15 & 2 e 3-metil-1 e 2-buteno & 1,2 & - & 8,9 & - & - & - \\
\hline 16 & etino & - & 31,5 & 10,5 & 2,4 & 3,4 & 7 \\
\hline 17 & hexano & - & 12,2 & - & 1,8 & 1 & - \\
\hline 18 & benzeno & - & 4,6 & - & 1,4 & - & 1,9 \\
\hline 19 & n-heptano & - & 3,3 & - & - & - & - \\
\hline 20 & i-buteno & - & 1,8 & - & - & - & - \\
\hline 21 & isopropilbenzeno & - & - & 3,2 & - & - & - \\
\hline 22 & nonano & - & - & 2,9 & - & 0,6 & - \\
\hline 23 & 2-metilheptano & - & - & 2,6 & - & - & - \\
\hline 24 & 1,2,4-TMB & - & - & 2,6 & 1,1 & - & - \\
\hline 25 & 1,3,5-TMB & - & - & 2,5 & - & - & - \\
\hline 26 & 2+3-metilpentano & - & - & - & - & - & 1,7 \\
\hline 27 & o-xileno & - & - & - & - & - & 0,8 \\
\hline 28 & etilbenzeno & - & - & - & - & - & 0,7 \\
\hline 29 & 2,2,4-TMpentano & - & - & - & 1,6 & - & - \\
\hline \multirow[t]{2}{*}{30} & isopreno & - & - & - & 1,1 & - & - \\
\hline & 2,3-dimetilbutano & - & - & - & - & 0,5 & - \\
\hline
\end{tabular}

a: este estudo; b: Blake e Rowland (1995); c: Hsieh e Tsai (2003); d: Qin et al (2007); Na e Kim (2001); f: Derwent et al. (2000). 


\section{Discussão}

levando-se em consideração a concentração média encontrada na atmosfera neste local estudado para o referido período, as dez espécies de COV mais abundantes foram: isopentano (6,21 ppbv), seguido de eteno (5,61 ppbv), formaldeído (5,00 ppbv), acetaldeído (4,00 ppbv), butano (3,40 ppbv), tolueno (2,86 ppbv), 1-buteno (2,57 ppbv), etano (2,5 ppbv), pentano (2,31 ppbv) e propano (2,09 ppbv), os quais somados representam $53 \%$ da totalidade dos $69 \mathrm{COV}$ determinados neste estudo. Segundo inventário da CETESB, a principal fonte de COV é o tubo de escapamento de veículos (produto de queima incompleta de combustíveis) representando 49,6\% da sua emissão, seguido por 43,1\% pela emissão do cárter e evaporativa, 4,2\% operações de transferência de combustível e 3,1\% da operação de processo industrial. O inventário de emissão para a RMSP é baseado nas informações disponíveis no ano-referência de 2006, período em que foi realizado este estudo.

Segundo o relatório da Cetesb, os fatores de emissão foram calculados a partir dos ensaios de emissão veicular realizados pela Cetesb e do Compilation of Air Pollutant Emission Factors, da Agência de Proteção Ambiental dos Estados Unidos -EPA (CETESB, 2007; 2010). A covariância entre as concentrações dos COV e as de CO demonstra que a principal fonte de COV no local estudado também é a emissão veicular, conforme pode ser verificado na Figura 2, pois tanto o CO como os COV são produtos da queima incompleta de combustíveis. Os alcanos foram os COV encontrados em maior abundância na atmosfera da RMSP, representando uma média de 45\%, seguido pelos alcenos com 26\%; os aromáticos, 14\%; os aldeídos, 13\% e os alcadienos, $2 \%$.

\section{Aldeídos}

Os aldeídos são importantes constituintes da troposfera urbana na RMSP (terceiro e quarto em concentração), pois contribuem em uma importante fração na totalidade dos COV. Segundo a International Agency for Research on Cancer - IARC (1998), o formaldeído é um composto classificado como classe 2A (provavelmente carcinogênico) e o acetaldeído como 2B (possivelmente carcinogênico). Eles são emitidos diretamente na atmosfera por fontes biogênicas e antropogênicas, além de poderem ser formados a partir de reações fotoquímicas.

Neste trabalho, encontrou-se uma razão média de 1,25 de formaldeído/acetaldeído, com a menor razão de 0,8 no horário das 6 às 8 horas. Neste horário, a luz solar é baixa e o formaldeído é apenas emitido pela fonte veicular na região estudada, não ocorrendo sua formação por meio das reações de fotólise. A maior razão foi encontrada no horário das 10 às 12 horas $(1,7)$, provavelmente pois neste horário há a contribuição primária (emissão veicular) e secundária (fotoquímica). A importância de comparar as razões formaldeído/acetaldeído no Brasil com outros países é devido à adição de etanol no combustível utilizado no Brasil. No Brasil, esta razão é baixa diferentemente de outros lugares, devido ao consumo de etanol como combustível, pois na queima do etanol ocorre maior emissão de acetaldeído do que formaldeído (CETESB, 2010). Na queima da gasolina sem adição de etanol, é emitido mais formaldeído do que acetaldeído. Para a frota veicular de 2006, o consumo de etanol como combustível veicular representava 47,5\%, mostrando que esta situação típica brasileira promove uma alteração na razão formaldeído/acetaldeído (CETESB, 2007). Em cidades como Ozaka (Japão), Burbank e Lenox (EUA), foram encontradas razões superiores de formaldeído/acetaldeído de 7,2; 6,23 e 32,2, respectivamente (ANDRADE, 2002).

No trabalho de Vasconcellos, Carvalho e Pool (2005), foram encontradas razões de 0,8 a 2,8 para amostras coletadas na Avenida Juscelino Kubitschek e razões de 0,24 a 0,91 foram encontradas para amostras coletadas nas proximidades do complexo viário Maria Maluf, na cidade de São Paulo, para medidas realizadas a cada duas horas, a partir das 8 até 16 horas, em 2001.

\section{Hidrocarbonetos}

Harrison (1998) concluiu em seu estudo que, numa população de um milhão de pessoas, seis podem desenvolver leucemia quando expostas a uma concentração do benzeno de 0,31 ppbv durante sua vida. O nível médio de benzeno encontrado neste estudo foi de 0,97 ppbv.

Benzeno, tolueno, etilbenzeno e xileno (BTEX) são grandes constituintes da composição atmosférica, emitidos por exaustão veicular, evaporação de combustíveis e solventes, queima de material orgânico etc. Estes hidrocarbonetos monoaromáticos são poderosos depressores do sistema nervoso central. O benzeno é considerado carcinogênico humano, classe 1 , por diversas organizações, tais como a IARC (1998) e a USEPA (1993). Os demais são classificados como provavelmente carcinogênicos, mutagênicos. O tolueno é o sexto composto de maior concentração encontrado nesta campanha e o benzeno é o $22^{\circ}$, cuja fonte majoritária é veicular.

Níveis ligeiramente mais elevados do benzeno foram registrados durante a década de 1990 na Europa (0,63 a 11,3 ppbv) e na Ásia (2,19 a 9,70 ppbv), e concentrações menores que 2,5 ppbv foram encontrados na América do Norte e Oceania. Na América do Norte, os conversores catalíticos são amplamente usados para controlar as emissões veiculares, resultando em concentrações menores de benzeno no ambiente, enquanto que, na Europa e na Ásia, a adoção de combustíveis isentos de chumbo, na última década, foi acompanhado de um aumento do índice de benzeno na gasolina (até 5\%). Os conversores catalíticos ainda estão sendo utilizados progressivamente (ALVES; TOMÉ, 2007).

A Tabela 2 compara as concentrações dos 15 COV mais abundantes em seis metrópoles no globo, incluindo os resultados deste estudo. As distinções entre as cidades apresentadas ocorrem devido à diferença de composição no combustível utilizado em cada 
localidade, tipo de veículos, além de fatores climáticos, geográficos etc. As espécies majoritárias são compostas por COV variando de C2 a C9. O tolueno aparece como um dos seis principais compostos em todas as cidades apresentadas. Os xilenos o, m e p estão entre os 15 compostos mais abundantes em São Paulo, Dallas, Seul e Londres. Em todas as cidades, os alcanos foram a classe de compostos emitidos em maior abundância. Em vários trabalhos, foram apontadas as fontes como: evaporação da gasolina, emissão de gás liquefeito do petróleo (GLP) e gás natural e a queima incompleta de combustíveis. Os hidrocarbonetos aromáticos, tolueno e m-p-xileno são provenientes tanto de emissão dos veículos como da utilização de solventes. Na cidade de São Paulo, a frota veicular é responsável por 97\% das emissões de hidrocarbonetos (HC). A cidade do México, localizada em um vale e com pouca ventilação, apresentou concentrações de COV 11 vezes superior à da cidade de São Paulo, dez vezes em relação à Seul e Londres, oito vezes em relação à Dallas e cinco vezes em relação à Taiwan. Gases como propano, i-butano e n-butano na cidade do México foram relacionados com o uso do GLP (BLAKE; ROWLAND, 1995; DERWENT et al., 2000; HSIEH; TSAI, 2003; NA; KIM, 2001; QIN et al., 2007).

\section{Formação de 0zônio}

A fim de avaliar a relação entre as concentrações de COV e a produção de $\mathrm{O}_{3}$ fotoquímico, utilizou-se a escala MIR do método de Carter (2000). Este método é baseado em um cenário modelo em que a formação de $\mathrm{O}_{3}$ é calculada sob condição máxima de formação, isto é, alto fluxo solar e um cenário em que as relações COV/NOx produzem máxima formação de $\mathrm{O}_{3}$. Também pode ser usado para determinar impactos absolutos e relativos da reatividade dos compostos orgânicos para a formação do $\mathrm{O}_{3}$ em relação a muitos tipos de COV que podem ser emitidos na atmosfera. A escala de reatividade MIR desenvolvida por Carter (2000) foi aplicada neste estudo para estimar o papel de cada COV identificado na formação de $\mathrm{O}_{3}$ na RMSP.

Cada espécie de COV possui um potencial diferente de formação de $\mathrm{O}_{3}$, e sua contribuição na formação deste dependerá tanto deste potencial como da concentração desta espécie na atmosfera.

Considerando a abundância e o potencial de formação de $\mathrm{O}_{3}$ para os COV quantificados, foram determinados os principais precursores de $\mathrm{O}_{3}$ na cidade de São Paulo, segundo a metodologia de Carter (2000; 2003).

Os dez compostos mais importantes na formação de $\mathrm{O}_{3}$ na cidade de São Paulo foram: 1-buteno (6,8\%), eteno (6,5\%), formaldeído $(6,1 \%)$, acetaldeído (5,5\%), tolueno (4,8\%), 1-etil-4-metilbenzeno $(3,7 \%)$, trans-2-penteno $(3,7 \%)$, propeno $(3,7 \%)$, trans-2-buteno (3,5\%) e 1-metilciclopenteno (3,5\%).

Compostos insaturados (com duplas ou triplas ligações) como alcenos, alcadienos, alcinos e aromáticos (benzenos di e tri-substituídos) são mais reativos e têm maior potencial na formação de $\mathrm{O}_{3} \mathrm{em}$ relação aos saturados, como os alcanos (com ligações simples). O fato de uma classe de COV ter maior concentração na atmosfera, como os alcanos, não significa que tenha um papel importante na formação do $\mathrm{O}_{3}$, pois neste aspecto a característica mais importante é sua reatividade. Como exemplo, os compostos 2-metil-butano, etano, butano e isobutano apresentam alta concentração na atmosfera da RMSP, porém não possuem um papel importante na formação do $\mathrm{O}_{3}$, conforme pode ser observado na Tabela 1. Eles representam 21\% do total de COV encontrado na atmosfera, no entanto, são responsáveis por $5 \%$ da formação do ozônio. Por outro lado, os compostos, como 1-etil-4-metilbenzeno e isopreno, apresentam baixa concentração na atmosfera, representando $2 \%$ do total de COV encontrado, porém, como são compostos de significante reatividade, representaram 7\% da formação do ozônio.

O isopreno é um composto particularmente importante por ser emitido tanto pelas plantas como pelos veículos. Ele está entre os 20 principais compostos que mais contribuem à formação de ozônio. Segundo estudo de Orlando et al. (2010), a medida mais efetiva para diminuição da concentração de $\mathrm{O}_{3}$ na atmosfera da RMSP seria a diminuição da concentração dos COV mais importantes na formação de $\mathrm{O}_{3}$, apresentados em ambos os trabalhos, tanto no referido artigo como neste estudo. Seu estudo também mostra que, em relação ao $\mathrm{NOx}$, ocorre exatamente o inverso, ao diminuir a concentração deste poluente, $\mathrm{o} \mathrm{O}_{3}$ aumentaria.

\section{Conclusão}

considerando os valores médios de concentração do período estudado, os dez compostos orgânicos mais abundantes encontrados, na região estudada, foram: isopentano (6,21 ppbv), eteno $(5,61$ ppbv), formaldeído (5,00 ppbv), acetaldeído (4,00 ppbv), butano (3,40 ppbv), tolueno (2,86 ppbv), 1-buteno (2,57 ppbv), etano (2,5 ppbv), pentano (2,31 ppbv) e propano (2,09 ppbv) e os principais precursores de $\mathrm{O}_{3}$ encontrados pertencem à classe de compostos alcenos, aldeídos e aromáticos, em que as dez espécies de maior importância, em ordem decrescente, foram: 1-buteno, eteno, acetaldeído, formaldeído, tolueno, 1-etil-4-metilbenzeno, trans-2-penteno, propeno, trans-2-buteno e 1-metilciclopenteno. A medida mais efetiva para diminuição da concentração de $\mathrm{O}_{3}$ na atmosfera da RMSP seria a diminuição da concentração dos COV mais importantes na formação de $\mathrm{O}_{3}$ apresentados neste estudo.

A redução e o estabelecimento do limite de emissão para alcenos e aromáticos das fontes veiculares podem contribuir para a diminuição substancial nas concentrações destes compostos na atmosfera da RMSP, considerados os principais precursores de $\mathrm{O}_{3}$, juntamente com os aldeídos que já têm valores limites estabelecidos para veículos do ciclo Otto.

Entretanto, é importante lembrar que, além da emissão veicular, outras fontes, como as emissões evaporativas que ocorrem no momento de recarga dos tanques dos veículos e dos postos de gasolina, são importantes fontes precursoras de $\mathrm{O}_{3}$ na RMSP. 


\section{Referências}

ABNT/INMETRO. Guia para a Expressão da Incerteza de Medição (GUM). Terceira edição brasileira em língua portuguesa. Rio de Janeiro: ABNT, INMETRO, 2003. 120 p.

ALVES, C.; TOMÉ M. Assessment Of Air Quality In Viana Do Castelo, Portugal, In The Scope Of The Polis Programme. Química Nova, v. 30, n. 7, p. 1555-1562, 2007

ANDRADE, M.V.A.S et al. Compostos Carbonílicos Atmosféricos: fontes, reatividade, níveis de concentração e efeitos toxicológicos. Química Nova, v. 25, n. 6b, p. 1117-1131, 2002.

BARLETTA, B. et al. Volatile organic compounds in 43 Chinese cities. Atmospheric Environment, v. 39, p. 5979-5990, 2005.

BLAKE, D.R.; ROWLAND, F.S. Urban leakage of liquefied petroleum gas and its impact on Mexico City air quality. Science, v. 269, p. 953-956, 1995

CARTER, W.P.L. (2003) The Saprc-99 Chemical Mechanism And Updated VOC Reactivity Scales. Disponível em: < http://pah.cert.ucr.edu/ carter/ reactdat.htm>. Acesso em: junho de 2007.

(2000) Documentation Of The Saprc-99 Chemical Mechanism For Voc Reactivity Assessment. Final Report to California Air Resources Board Contract n 92-329, and (in part) 95.

COMPANHIA DE ENGENHARIA DE TRÁFEGO (CET). Disponível em: $<$ http://cetsp1.cetsp.com.br/monitransmapa/agora/>. Acesso em: 20 out. 2006

COMPANHIA DE TECNOLOGIA DE SANEAMENTO AMBIENTAL (CETESB). Relatório de Qualidade do Ar no Estado de São Paulo - 2009, série ISSN 0103-4103, 2010.

Relatório de Qualidade do Ar no Estado de São Paulo - 2006, série ISSN 0103-4103, 2007.

DERWENT, R.G. et al. Analysis and interpretation of the continuous hourly monitoring data for 26 C2-C8 hydrocarbons at 12 United Kingdom sites during 1996. Atmospheric Environment, v. 34, p. 297-312, 2000.

GROSJEAN, E.; RASMUSSEN, R. A.; GROSJEAN, D. Ambient levels of gas phase pollutants in Porto Alegre, Brazil. Atmospheric Environment, v. 32, n. 20, p. 3371-3379, 1998

GUO, H. et al. Regional and local contributions to ambient nonmethane volatile organic compounds at a polluted rural/ coastal site in Pearl River Delta, China. Atmospheric Environment, v. 40, p. 2345-2359, 2006.

HARRISON, R.M. In Air Pollution and Health, Issues in Environmental Science and Technology. The Royal Society of Chemistry, p. 57-73, 1998.

HSIEH, C.C.; TSAI, J.H. VOC concentration characteristics in Southern Taiwan. Chemosphere, v. 50, p. 545-556, 2003.
INTERNATIONAL AGENCY FOR RESEARCH ON CANCER (IARC). Monographs on the Evaluation of Carcinogenic Risk to Humans, France, v. $45,1998$.

LANGFORD, B. et al. Fluxes and concentrations of volatile organic compounds above London. Atmospheric Chemistry and Physics, v. 10, p. $627-645,2010$.

MACHADO, S.C. Qualidade do ar da Cidade do Rio de Janeiro: Sinergia entre Simulação e Monitoramento. Tese (Doutorado) - Universidade Federal do Rio de Janeiro, Rio de Janeiro, 2003.

NA, K.; KIM, Y.P. Seasonal characteristics of ambient volatile organic compounds in Seoul. Atmospheric Environment, v. 35, p. 2603-2614, 2001.

OLSZYK, D.M.; THOMPSON, C.R.; POE, M.P. Crop Loss Assessment for California: Modeling Losses with Different Ozone Standard Scenarios. Environmental Pollution, v. 53, p. 303-311, 1988.

ORLANDO, J.P. et al. Ozone precursors for the São Paulo Metropolitan Area. Science of the Total Environment, v. 408, p. 1612-1620, 2010

PRETTO, A. O estudo do comportamento dos gases-traço $\mathrm{O}_{3}, \mathrm{NO}_{x^{\prime}} \mathrm{CO}$, $\mathrm{SO}_{2}$ e de COV na atmosfera da cidade de São Paulo. Tese (Doutorado) - Universidade de São Paulo, São Paulo, 2004.

QIN, Y. et al. C2-C10 nonmethane hydrocarbons measured in Dallas, USA-Seasonal trends and diurnal characteristics. Atmospheric Environment, v. 41, p. 6018-6032, 2007.

SEINFELD, J.H.; PANDIS, S.N. Atmospheric Chemistry and Physics From Air Pollution to Climate Change. 2 ed. Nova lorque: John Wiley \& Sons, 2006. 1203p.

USEPA. Compendium Method TO-15A - Determination of Volatile Organic Compounds (VOC) in Air Collected in Specially-Prepared Canisters And Analyzed by Gas Chromatography/ Mass Spectrometry, Center for Environmental Research Information, 2 ed., Cincinnati, $\mathrm{OH} 45268$, EPA/625/R-96/010b, 1999.

Compendium Method TO-11A. Determination of Formaldehyde in Ambient Air Using Adsorbent Cartridge Followed by High Performance Liquid Chromatography (HPLC). EPA-625/R-96/010b. Cincinnati, OH: U.S. Environmental Protection Agency, 1997.

Integrated Risk Information System (IRIS) on Benzene. Environmental Criteria and Assessment Office, Office of Health and Environmental Assessment, Office of Research and Development, Cincinnati, OH, 1993.

VASCONCELLOS, P.C.; CARVALHO, L.R.F.; POOL, C.S. Volatile Organic Compounds Inside Urban Tunnels of São Paulo City, Brazil. Journal of the Brazilian Chemical Society, v. 16, p. 1210-1216, 2005. 